\title{
LETTERS
}

\section{Healthy interpretation is crucial}

Thank you for this important article. ${ }^{1}$ Prior to medical school, I worked as a certified American Sign Language interpreter. Walji and Flegel's ${ }^{1}$ point about ad hoc interpreters is right on. You can imagine a situation in the emergency department where a patient with abdominal pain and fever is not going to want to reveal her recent sexual affair with a stranger, vaginal discharge and a recent missed period to her daughter who is doing the interpretation. In the medical setting, family interpreters should be avoided if possible.

Another issue is sometimes seen in immigrants, patients who are deaf or those patients born in Canada who do not commonly use English (e.g., Indigenous elders) is that incidental learning may not be the same as it is in patients who understand and speak English. This means that issues talked about regularly on television and at the coffee machine at work, and ads seen on bus shelters, for example, may not be available to the patient in front of you. When you talk to them about the need for a Pap smear, colonoscopy, HIV test, etc. they may have little or no awareness of these issues and what they are all about.

The last point not mentioned in the article is that there are frequent important cultural issues related to interpretation. Having a professional and skilled interpreter is important when cultural concerns might be present.

Thank you for bringing an important topic to the fore.

\section{Michael Stephensen MD}

Family physician, Winnipeg, Man.

- Cite as: CMAJ 2018 February 20;190:E199. doi: 10.1503/cmaj.733529

\section{Reference}

1. Walji M, Flegel K, Brent GA, et al. Healthy interpretation. CMAJ 2017;189:E1273.

Competing interests: None declared. 